OPEN ACCESS

Check for updates FAST TRACK

${ }^{1}$ School of Public Health, Fudan University, Key Laboratory of Public Health Safety, Ministry of Education, 138 Yixueyuan Road, Xuhui District, 200032 Shanghai, China

${ }^{2}$ Division of International Epidemiology and Population Studies, Fogarty International Center, National Institutes of Health, Bethesda, MD, USA

${ }^{3}$ Department of Epidemiology and Biostatistics, Indiana University School of Public Health, Bloomington, IN, USA ${ }^{4}$ Laboratory for the Modeling of Biological and Sociotechnical Systems, Northeastern University, Boston, MA, USA

Correspondence to:

H Yu yhj@fudan.edu.cn (ORCID 0000-0002-6335-5648)

Additional material is published online only. To view please visit the journal online.

Cite this as: BMJ 2020;371:m4704 http://dx.doi.org/10.1136/bmj.m4704

Accepted: 3 December 2020

\section{Global, regional, and national estimates of target population sizes for covid-19 vaccination: descriptive study}

\author{
Wei Wang, ${ }^{1}$ Qianhui Wu, ${ }^{1}$ Juan Yang, ${ }^{1}$ Kaige Dong, ${ }^{1}$ Xinghui Chen, ${ }^{1}$ Xufang Bai, ${ }^{1}$ Xinhua Chen, ${ }^{1}$ \\ Zhiyuan Chen, ${ }^{1}$ Cécile Viboud, ${ }^{2}$ Marco Ajelli, ${ }^{3,4}$ Hongjie $\mathrm{Yu}^{1}$
}

\section{ABSTRACT}

OBJECTIVE

To provide global, regional, and national estimates of target population sizes for coronavirus disease 2019 (covid-19) vaccination to inform country specific immunisation strategies on a global scale.

DESIGN

Descriptive study.

SETTING POPULATION

Target populations for covid-19 vaccination based on country specific characteristics and vaccine objectives (maintaining essential core societal services; reducing severe covid-19; reducing symptomatic infections and stopping virus transmission).

\section{MAIN OUTCOME MEASURE}

Size of target populations for covid-19 vaccination. Estimates use country specific data on population sizes stratified by occupation, age, risk factors for covid-19 severity, vaccine acceptance, and global vaccine production. These data were derived from a multipronged search of official websites, media sources, and academic journal articles.

RESULTS

Target population sizes for covid-19 vaccination vary markedly by vaccination goal and geographical region. Differences in demographic structure, presence of underlying conditions, and number of essential workers lead to highly variable estimates of target populations at regional and country levels. In
194 member states of the World Health Organization.

\section{WHAT IS ALREADY KNOWN ON THIS TOPIC}

Ethical frameworks to guarantee fair allocation of coronavirus disease 2019 (covid-19) vaccines globally have been described in previous studies

One of these studies also modelled optimal vaccine allocation strategies for different objectives using optimisation algorithms

Population sizes for covid-19 vaccination programmes targeting specific demographics, occupations, or high risk people (such as essential workers and those with pre-existing conditions) are needed

\section{WHAT THIS STUDY ADDS}

Target population sizes for covid-19 vaccination vary markedly by vaccination goal and geographical region

Owing to geographical heterogeneity, regional and country specific allocation strategies should be designed to maintain functional societies, minimise covid-19 burden, and reduce severe acute respiratory syndrome coronavirus 2 (SARS-CoV-2) transmission

Estimates of target population sizes can guide relevant stakeholders in the development of fair and equitable allocation strategies particular, Europe has the highest share of essential workers (63.0 million, $8.9 \%$ ) and people with underlying conditions (265.9 million, 37.4\%); these two categories are essential in maintaining societal functions and reducing severe covid-19, respectively. In contrast, South East Asia has the highest share of healthy adults (777.5 million, 58.9\%), a key target for reducing community transmission. Vaccine hesitancy will probably impact future covid-19 vaccination programmes; based on a literature review, $68.4 \%$ ( $95 \%$ confidence interval $64.2 \%$ to $72.6 \%$ ) of the global population is willing to receive covid-19 vaccination. Therefore, the adult population willing to be vaccinated is estimated at 3.7 billion ( $95 \%$ confidence interval 3.2 to 4.1 billion).

\section{CONCLUSIONS}

The distribution of target groups at country and regional levels highlights the importance of designing an equitable and efficient plan for vaccine prioritisation and allocation. Each country should evaluate different strategies and allocation schemes based on local epidemiology, underlying population health, projections of available vaccine doses, and preference for vaccination strategies that favour direct or indirect benefits.

\section{Introduction}

As coronavirus disease 2019 (covid-19) continues to spread across the world, a total of 273 candidate vaccines for covid-19 are in development and twelve have entered phase III clinical trials as of 4 December 2020 . $^{1}$ Hopes are high to bring one or more vaccine candidates to the market by the end of the year. Despite 65.0 million cases reported so far, ${ }^{2}$ most of the world population still remains susceptible. Several seroepidemiological studies have reported low seroprevalence of antibodies to severe acute respiratory syndrome coronavirus 2 (SARS-CoV-2), in the range of $1.0-10.8 \%,^{3-5}$ although higher proportions have been reported locally (eg, approximately 20\% in New York City, United States ${ }^{6}$ ). Therefore, a large demand for covid-19 vaccines is expected during the next year.

Twelve covid-19 vaccine manufacturers have announced their plans for vaccine production, with an estimated capacity of approximately 10 billion doses by the end of $2021 .^{7-14}$ However, even in the highly optimistic scenario that 10 billion doses are effectively manufactured, with a two dose regimen (which is planned for most current covid-19 candidates), the existing annual production capacity ${ }^{14}$ is too limited to achieve herd immunity on a global scale (60$80 \%$ of the world population ${ }^{15}$ ). Therefore, defining priority groups for vaccination is necessary. Important 
questions remain about equitable and efficient distribution of covid-19 vaccines because many low and middle income countries lack covid-19 vaccine research, development, and production capacities. ${ }^{16}$ To ensure equitable access to covid-19 vaccines, COVAX (the vaccine pillar of the Access to Covid-19 Tools Accelerator) has been established, with global cooperation to ensure availability to higher and lower income countries. ${ }^{17}$ Additionally, because there will probably be an initial period of vaccine shortage, experts in the US ${ }^{16}{ }^{18}$ and the United Kingdom ${ }^{19}$ have developed country specific interim frameworks for covid-19 vaccine allocation and distribution. However, information is lacking about the number of vaccine doses that each region and country needs, and this could hamper equitable and efficient allocation and distribution of covid-19 vaccines.

We used the allocation frameworks proposed by various international teams ${ }^{16} 18-20$ to provide global, regional, and national estimates of target population sizes for covid-19 vaccination by priority group. The vulnerability of each country to covid-19 is based on factors such as geographical location, disease burden, the likelihood of an outbreak, and the potential for severe covid-19 health impacts. Population groups can be categorised into different allocation tiers according to broad vaccine objectives. The three vaccine objectives that have been considered so far are (a) to maintain core societal functions, (b) to minimise deaths, and (c) to reduce transmission. ${ }^{16} 1820$ Estimates of target population sizes based on these objectives can guide relevant stakeholders in the development of fair and equitable allocation strategies and inform local vaccination programmes.

\section{Methods \\ Definition of target populations for covid-19 vaccination}

We rely on previously proposed international allocation schemes for pandemic covid-19 vaccines that have endorsed three fundamental objectives (fig 1) ${ }^{1618-20}$ :

- To maintain essential core societal functions during the covid-19 pandemic, such as essential health services and food delivery

- To protect people from irreversible and devastating harm, such as death and severe covid-19 that causes long term organ damage (eg, lung, kidney, and liver)

- To control community transmission, enabling a return to baseline prepandemic economic and social activities.

The first vaccine allocation scheme targets essential workers, which extends beyond healthcare workers. $^{21}$ Essential workers might include, but are not limited to, workers in the food industry and domestic transportation, police and military staff who maintain public safety, and workers who maintain electricity, water, fuel, information, and financial infrastructures.
The second vaccine allocation scheme targets people who might experience irreversible and devastating harm from covid-19 (that is, admission to hospital, admission to critical care, and death). Target populations include people older than 65 years, those with high risk health conditions, and those in close contact with people at very high risk of poor outcomes (eg, staff in nursing homes and long term care facilities). ${ }^{1820}$ We considered people with the following underlying conditions: cardiovascular disease, chronic kidney disease, chronic respiratory disease, chronic liver disease, diabetes, cancer with direct immunosuppression, cancer without direct immunosuppression but with possible immunosuppression caused by treatment, HIV or AIDS, tuberculosis (excluding latent infections), chronic neurological disorders, and sickle cell disorders. ${ }^{22}$ We also considered people older than 60 years without any underlying conditions and pregnant women. Given age specific susceptibility to SARS-CoV-2 infection, ${ }^{23}$ we then reclassified people with and without underlying conditions into different groups according to their age: people aged 60 years or older with at least one underlying condition; people younger than 60 years with at least one underlying condition; people aged 80 years or older without any underlying conditions; and people aged 60-79 years without any underlying conditions.

A third possible vaccine allocation scheme focuses on reducing SARS-CoV-2 transmission; in this case, high transmission groups should be targeted. ${ }^{20}$ Target populations include adults and children involved in economic or educational activities who experience higher risk of economic or educational harm from not working or going to school. These adults and children also have a higher probability of transmission when going back to work or school because of their large number of contacts. ${ }^{20}$ 23-25 To reduce symptomatic infections and to stop virus transmission, vaccination should extend to all people younger than 60 years without any underlying conditions. These people can be further reclassified into three groups (aged 20-59 years, aged 5-19 years, and aged 0-4 years) on the basis of their risk of transmitting the virus, and projected economic harm from not working when considering the adult groups. ${ }^{23}$

Because children have not been eligible to participate in phase III covid-19 vaccine trials conducted so far, first generation covid-19 vaccines are less likely to be licensed for children and this age group is unlikely to be prioritised for immunisation. Accordingly, all people younger than 20 years were excluded from the main analysis and reported only in a sensitivity analysis to provide a fuller picture of target population sizes across the globe.

\section{Data sources}

To estimate the size of the priority groups for vaccination by country, we extracted country specific information from the following publicly available sources covering the period 2013-20 (table S1): 


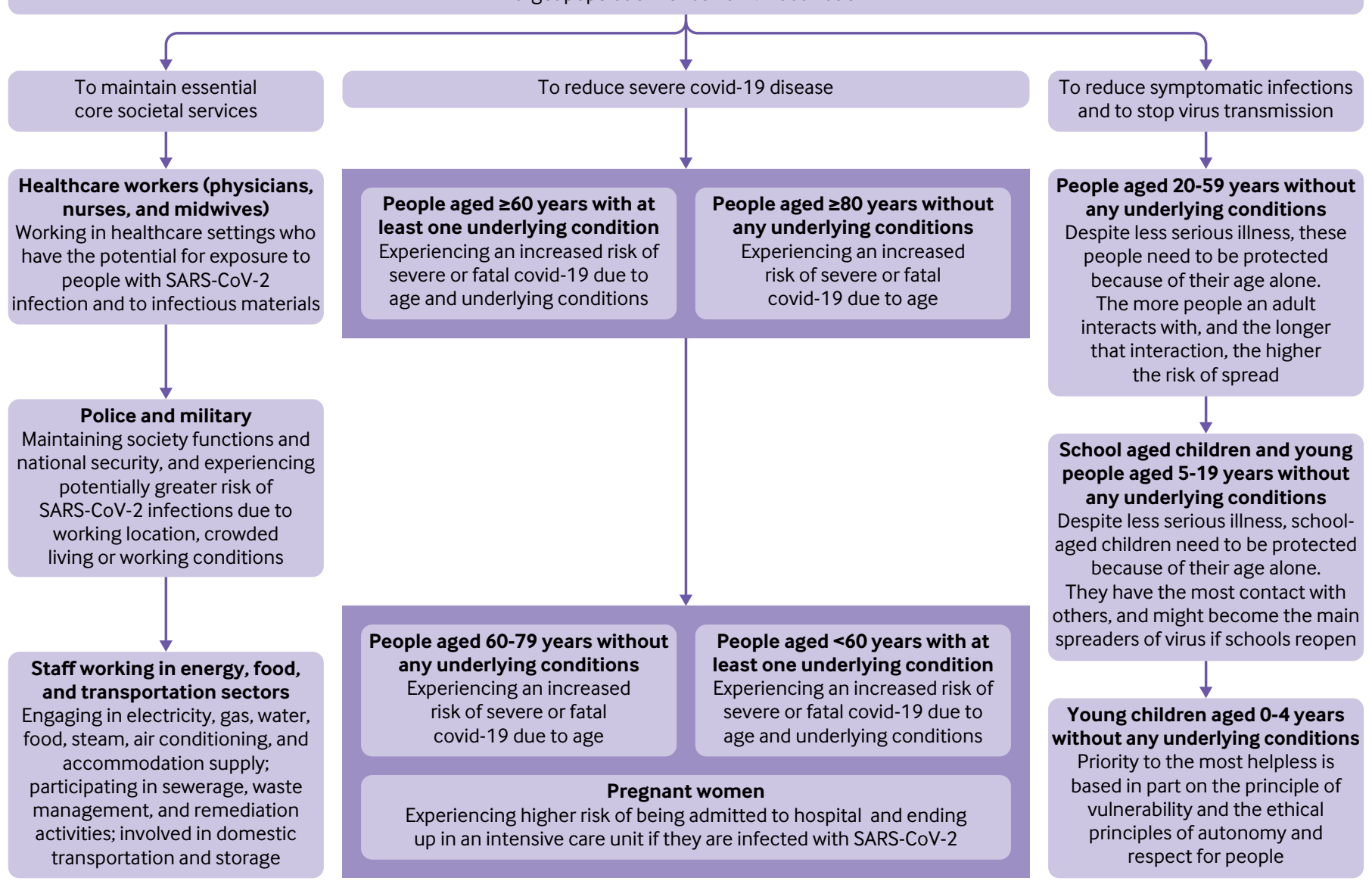

Fig 1 | Priority groups for covid-19 vaccination. Covid-19=coronavirus disease 2019; SARS-CoV-2=severe acute respiratory syndrome coronavirus 2

- United Nations mid-year population estimates for 2020 for 194 WHO member states (and countries or territories)

- $\quad$ Size of the military populations from the World Bank Group, supplemented by Baidu, Bing, and Google search queries by using the term "military size" and country name

- Density of physicians, nurses, and midwives from the World Bank and the World Health Organization

- Number of people working in the electricity, gas, water, steam, and air conditioning sectors, and food, accommodation, domestic transportation, and storage industries by using census data on economically active populations in 152 countries

- $\quad$ Age specific number of people at increased risk of severe covid-19 from previous report by Clark and colleagues. $^{22}$

Two independent investigators applied the same search procedure for crosschecking and comprehensiveness.

\section{Multiple imputation of missing data}

Up to $50(25.8 \%)$ countries had missing values (table S2 shows the completeness analysis) for the number of essential workers who ensure basic life needs. Therefore, we used a state-of-the-art multivariate imputation by chained equations algorithm ${ }^{26}$ to impute missing values in the database. The number of multiple imputations was set at five, with each imputation running five realisations. For each of the five realisations of imputed databases, we independently performed regression analysis on the size of each essential worker subgroup by using UN mid-year population, gross domestic product per capita (current US\$), and UN geographical regions as covariates, which are key determinants of such populations. We then considered uncertainty in our computations by using five imputed databases to obtain the mean predictive values and 95 percentile bootstrap confidence intervals based on 10000 bootstrap samples.

\section{Estimates of target population for covid-19 vaccination}

We obtained global and regional estimates of each target population by summing the relevant population groups stratified by vaccination goal in our full sample of 194 countries. Country level estimates of target population sizes are reported for 104 countries (5.8 billion people, $74.4 \%$ of the total population), with complete data directly retrieved from official statistics. We do not present national data for 90 countries; for these countries, we either relied on multiple imputation to infer some of the population strata $(n=50$ countries, 
covering 1.3 billion people, representing $16.5 \%$ of the world population) or we used non-official sources for numbers of police and military staff $(n=49$, about 1.4 billion people, $18.2 \%$ of the world population). However, police and military staff in those 49 countries account for only $0.03-1.1 \%$ of the total population of each country, and therefore have a limited impact on global and regional estimates of target populations.

To avoid overlap between the essential workers group and adults aged 20-59 years without any underlying conditions, we subtracted those engaging in essential work activities from the broader group of healthy adults. Additionally, data on age specific prevalence of underlying conditions were lacking for 11 countries. In the main analysis, we assumed that the age specific prevalence of underlying conditions in countries with missing data was the same as the WHO regional average. Then, the number of people with and without underlying conditions at a given age is equal to the prevalence of underlying conditions multiplied by the corresponding population size. The appendix reports a sensitivity analysis in which we assume that the number of people without any underlying conditions corresponds to the total number of people of that age, if no data exist.

In a sensitivity analysis, we considered the possibility that countries might want to exclude people who have a history of SARS-CoV-2 vaccination from priority groups. Therefore, we collected data on the number of people with covid-19 as of 10 November 2020 and examined serology surveys. We found data on the number of people who tested positive for SARS-CoV-2 by reverse transcription polymerase chain reaction $(n=182$ countries) or serological assays $(n=63)$ from

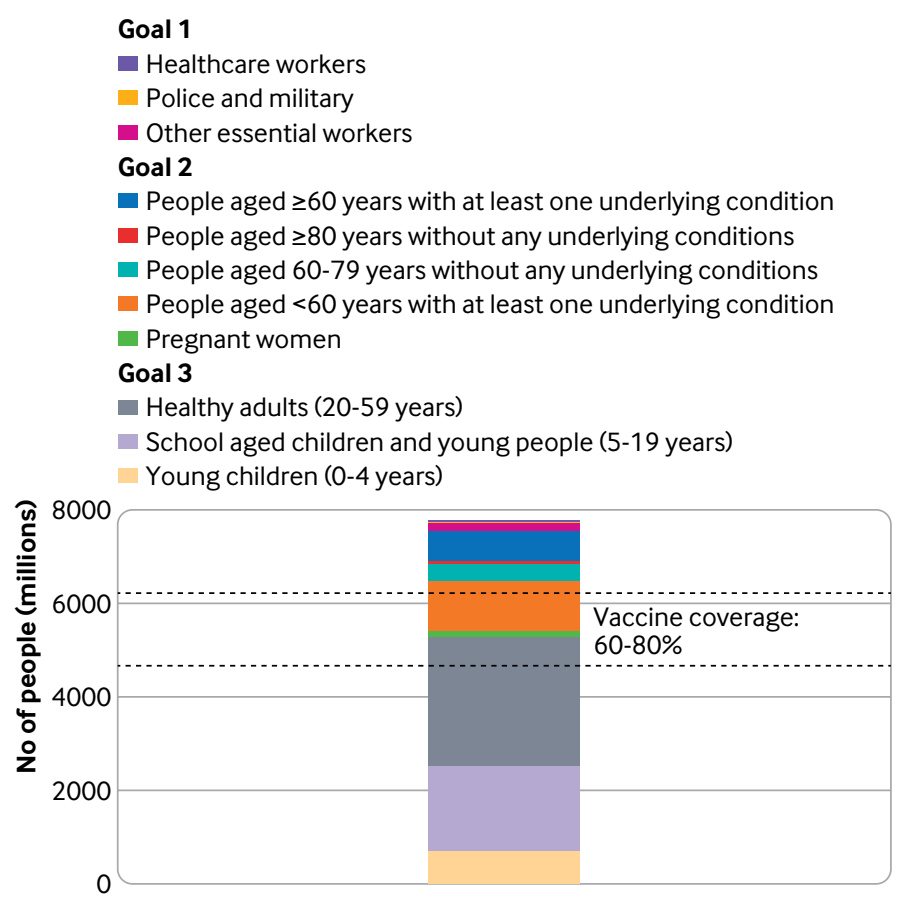

Fig 2 | Global estimates of target population sizes for covid-19 vaccination by goal of vaccination programmes. Covid-19=coronavirus disease 2019 published literature ${ }^{6}$ and official reports (table S4). The number of serologically confirmed cases in a country was estimated as the seroprevalence of SARSCoV-2 multiplied by the corresponding population size. Additionally, we ran two sensitivity analyses to account for vaccine hesitancy and delivery issues. We performed a meta-analysis to review willingness to accept a covid-19 vaccine (see below) and we assumed vaccination coverage of $60-80 \%$ according to previous work. $^{27}$

\section{Estimates of willingness to accept a covid-19 vaccine}

To estimate the willingness of the population to accept a covid-19 vaccine, we performed a systematic review and meta-analysis. We queried PubMed, Embase, Web of Science, and MedRxiv using the following terms: "COVID-19 AND (accept* OR hesitancy OR attitude OR preference).” We identified 30 relevant studies (fig $\mathrm{S} 1)$. We then used random effects models to estimate the acceptance rate on national and regional scales. For countries without reports on the acceptance of a covid-19 vaccination, the acceptance rate was assumed to be the same as the WHO regional average.

Estimates of covid-19 vaccine production capacity We searched the web for information on the expected production capacity of major pharmaceutical companies currently running phase III vaccination trials. We retrieved information from 12 companies (table S9) and summed the reported capacities to obtain an upper bound estimate of the vaccine production capacity, standing at around 10 billion doses by the end of 2021. However, this figure is probably an overestimate because it does not account for the following factors: some vaccine candidates might not be licensed by the end of 2021, some might be dropped owing to lack of effectiveness, and production chains could suffer unexpected delays.

\section{Patient and public involvement}

This research did not involve consultation with patients or the public.

\section{Results}

\section{Global prospective}

We start by evaluating the full scope of a universal vaccine programme that does not have priority groups. The global target population would be 7.8 billion people (fig 2). If young children (0-4 years) and school aged children and young people (5-19 years) were not initially prioritised or eligible for vaccination, the target population would be 5.2 billion people $(95 \%$ confidence interval 5.1 to 5.2 billion; table 1 ).

By analysing and modelling national, regional, and country specific data on occupation, demography, and health conditions, we can parse out the total population in different priority groups based on three main vaccination objectives. If vaccines are preferentially allocated to priority workers to help maintain societal functions, the global target population is 258.3 million 


\begin{tabular}{|c|c|c|c|c|c|c|c|}
\hline & \multirow[b]{2}{*}{ All } & \multicolumn{6}{|c|}{ WHO region (millions) } \\
\hline & & Africa & Americas & $\begin{array}{l}\text { Eastern } \\
\text { Mediterranean }\end{array}$ & Europe & Western Pacific & South East Asia \\
\hline \multicolumn{8}{|c|}{ Maintaining essential core societal services } \\
\hline Subtotal & $\begin{array}{l}258.3 \\
(241.7 \text { to } 279.7)\end{array}$ & $\begin{array}{l}25.4 \\
(19.1 \text { to } 33.7) \\
\end{array}$ & $\begin{array}{l}44.5 \\
(41.9 \text { to } 47.5)\end{array}$ & $\begin{array}{l}31.9 \\
(27.8 \text { to } 37.4)\end{array}$ & $\begin{array}{l}63.0 \\
(62.2 \text { to } 64.0) \\
\end{array}$ & $\begin{array}{l}58.8 \\
\text { (58.7 to } 58.8) \\
\end{array}$ & $\begin{array}{l}34.8 \\
\text { (31.9 to } 38.2) \\
\end{array}$ \\
\hline Healthcare workers & 40.7 & 1.4 & 10.9 & 1.8 & 10.8 & 10.6 & 5.2 \\
\hline Police and military* & 46.9 & 3.2 & 8.0 & 6.1 & 8.4 & 10.7 & 10.4 \\
\hline $\begin{array}{l}\text { Other occupational } \\
\text { population }\end{array}$ & $\begin{array}{l}170.7 \\
\text { (154.1 to } 192.1)\end{array}$ & $\begin{array}{l}20.7 \\
\text { (14.4 to } 29.1)\end{array}$ & $\begin{array}{l}25.6 \\
(23.1 \text { to } 28.6)\end{array}$ & $\begin{array}{l}24.0 \\
\text { (19.9 to } 29.6)\end{array}$ & $\begin{array}{l}43.8 \\
(43.0 \text { to } 44.8)\end{array}$ & $\begin{array}{l}37.5 \\
(37.4 \text { to } 37.5)\end{array}$ & $\begin{array}{l}19.1 \\
(16.2 \text { to } 22.5)\end{array}$ \\
\hline \multicolumn{8}{|l|}{ Reducing severe covid-19 } \\
\hline Subtotal & 2145.0 & 206.3 & 301.9 & 158.2 & 345.7 & 626.2 & 506.8 \\
\hline $\begin{array}{l}\text { People aged } \geq 60 \text { years } \\
\text { with at least one } \\
\text { underlying condition }\end{array}$ & 657.6 & 35.8 & 113.1 & 35.9 & 144.8 & 197.9 & 130.2 \\
\hline $\begin{array}{l}\text { People aged } \geq 80 \text { years } \\
\text { without any underlying } \\
\text { conditions }\end{array}$ & 28.6 & 0.8 & 4.5 & 0.8 & 7.3 & 10.8 & 4.4 \\
\hline $\begin{array}{l}\text { People aged 60-79 years } \\
\text { without any underlying } \\
\text { conditions }\end{array}$ & 354.1 & 19.0 & 51.2 & 15.8 & 61.5 & 132.0 & 74.6 \\
\hline $\begin{array}{l}\text { People aged } 20-59 \text { years } \\
\text { with at least one } \\
\text { underlying condition }\end{array}$ & 962.7 & 111.6 & 118.2 & 87.0 & 121.1 & 262.8 & 262.0 \\
\hline Pregnant women & 142.0 & 39.1 & 14.9 & 18.7 & 11.0 & 22.7 & 35.6 \\
\hline \multicolumn{8}{|c|}{ Reducing symptomatic infections and stopping virus transmissiont } \\
\hline Subtotal & $\begin{array}{l}2761.0 \\
(2739.6 \text { to } 2777.6)\end{array}$ & $\begin{array}{l}304.2 \\
(295.9 \text { to } 310.5)\end{array}$ & $\begin{array}{l}373.1 \\
(370.1 \text { to } 375.6)\end{array}$ & $\begin{array}{l}231.6 \\
(226.1 \text { to } 235.7)\end{array}$ & $\begin{array}{l}303.0 \\
(302.0 \text { to } 303.7)\end{array}$ & $\begin{array}{l}771.5 \\
(771.5 \text { to } 771.6)\end{array}$ & $\begin{array}{l}777.5 \\
(774.1 \text { to } 780.5)\end{array}$ \\
\hline Adults without conditions & $\begin{array}{l}2761.0 \\
(2739.6 \text { to } 2777.6)\end{array}$ & $\begin{array}{l}304.2 \\
(295.9 \text { to } 310.5)\end{array}$ & $\begin{array}{l}373.1 \\
(370.1 \text { to } 375.6)\end{array}$ & $\begin{array}{l}231.6 \\
(226.1 \text { to } 235.7)\end{array}$ & $\begin{array}{l}303.0 \\
(302.0 \text { to } 303.7)\end{array}$ & $\begin{array}{l}771.5 \\
(771.5 \text { to } 771.6)\end{array}$ & $\begin{array}{l}777.5 \\
\text { (774.1 to } 780.5) \\
\end{array}$ \\
\hline Total & $\begin{array}{l}5164.3 \\
(5126.3 \text { to } 5202.3)\end{array}$ & $\begin{array}{l}535.9 \\
(521.2 \text { to } 550.5)\end{array}$ & $\begin{array}{l}719.4 \\
(713.8 \text { to } 725.0)\end{array}$ & $\begin{array}{l}421.6 \\
(412.0 \text { to } 431.2)\end{array}$ & $\begin{array}{l}711.7 \\
(710.0 \text { to } 713.5)\end{array}$ & $\begin{array}{l}1456.5 \\
(1456.4 \text { to } 1456.6)\end{array}$ & $\begin{array}{l}1319.2 \\
(1312.9 \text { to } 1325.5)\end{array}$ \\
\hline
\end{tabular}

(95\% confidence interval 241.7 to 279.7 million), including 40.7 million (15.8\%) healthcare workers, 46.9 million (18.2\%) police and military staff, and 170.7 million $(66.1 \%$; $95 \%$ confidence interval 154.1 to 192.1 million; $63.8 \%$ to $68.7 \%$ ) people who maintain critical infrastructure and other important services. This figure represents 5.0\% (95\% confidence interval $4.7 \%$ to $5.4 \%$ ) of the total population (table 1 ).

Among the 2.2 billion adults at risk of severe covid-19 who need to be vaccinated to minimise the health burden of covid-19 (approximately $41.5 \%$ of the total population), 1.6 billion people (approximately $31.4 \%$ of the total population) had at least one underlying condition, followed by those aged 60 years or older without any underlying conditions (0.4 billion, $7.4 \%$ ), and pregnant women ( 0.1 billion, $2.7 \%)$. The estimated size of the general population aged 20-59 years without any underlying conditions is estimated at 2.8 billion (approximately $53.5 \%$ of the total population; table 1 ).

We emphasise that any vaccination programme is not expected to reach $100 \%$ of the population owing to several factors. In particular, if we assume that people who have experienced a natural SARS-CoV-2 infection might not be considered as a priority for vaccination, the total target population decreases to 4.78 billion (95\% confidence interval 4.75 to 4.82 billion; table S4). Vaccine hesitancy might be another important factor. The result of our meta-analysis (which includes 30 papers) found that $68.4 \%$ (95\% confidence interval $64.2 \%$ to $72.6 \%$ ) of the population is willing to receive covid-19 vaccination (fig S1). If we take this estimate into account, the target population that is willing to be vaccinated is estimated at 3.7 billion (95\% confidence interval 3.2 to 4.1 billion; table S5). Overall, by considering vaccination coverage of $60-80 \%$, which includes the herd immunity threshold and vaccine hesitancy estimates, the size of the target population is 3.1-4.1 billion people (table 2).

\section{Regional perspectives}

We observed geographical disparities in the share of different target population groups across WHO regions. If we consider the target for vaccination is the entire population (no prioritisation by occupation or risk group), South East Asia (1.3 billion, 25.5\%) and the Western Pacific (1.5 billion, 28.2\%) together account for $53.7 \%$ of the population to vaccinate. The target populations across other regions are $10.4 \%$ for Africa (0.5 billion), 13.9\% for the Americas (0.7 billion), $13.8 \%$ for Europe (0.7 billion), and 8.2\% for the Eastern Mediterranean ( 0.4 billion; table 1$)$.

Similarly, the size of the target population to maintain essential societal functions varies considerably by region. Highest concentrations are in Europe (63.0 million people, 24.4\%), the Western 


\begin{tabular}{|c|c|c|c|c|c|c|c|}
\hline \multirow[b]{2}{*}{ Vaccination coverage and goals of vaccination } & \multirow[b]{2}{*}{ All } & \multicolumn{6}{|c|}{ WHO region (millions) } \\
\hline & & Africa & Americas & $\begin{array}{l}\text { Eastern } \\
\text { Mediterranean }\end{array}$ & Europe & Western Pacific & South East Asia \\
\hline \multicolumn{8}{|l|}{$60 \%$} \\
\hline \multicolumn{8}{|l|}{ Maintaining essential core societal services } \\
\hline Subtotal & 155.0 & 15.2 & 26.7 & 19.1 & 37.8 & 35.3 & 20.9 \\
\hline Healthcare workers & 24.4 & 0.8 & 6.5 & 1.1 & 6.5 & 6.4 & 3.1 \\
\hline Police and military* & 28.1 & 1.9 & 4.8 & 3.7 & 5.0 & 6.4 & 6.2 \\
\hline Other occupational population & 102.4 & 12.4 & 15.4 & 14.4 & 26.3 & 22.5 & 11.5 \\
\hline \multicolumn{8}{|l|}{ Reducing severe covid-19 } \\
\hline Subtotal & 1287.0 & 123.8 & 181.1 & 94.9 & 207.4 & 375.7 & 304.1 \\
\hline $\begin{array}{l}\text { People aged } \geq 60 \text { years with at least one } \\
\text { underlying condition }\end{array}$ & 394.6 & 21.5 & 67.9 & 21.5 & 86.9 & 118.7 & 78.1 \\
\hline $\begin{array}{l}\text { People aged } \geq 80 \text { years without any } \\
\text { underlying conditions }\end{array}$ & 17.2 & 0.5 & 2.7 & 0.5 & 4.4 & 6.4 & 2.6 \\
\hline $\begin{array}{l}\text { People aged } 60-79 \text { years without any } \\
\text { underlying conditions }\end{array}$ & 212.5 & 11.4 & 30.7 & 9.5 & 36.9 & 79.2 & 44.8 \\
\hline $\begin{array}{l}\text { People aged } 20-59 \text { years with at least one } \\
\text { underlying condition }\end{array}$ & 577.6 & 67.0 & 70.9 & 52.2 & 72.7 & 157.7 & 157.2 \\
\hline Pregnant women & 85.2 & 23.5 & 8.9 & 11.2 & 6.6 & 13.6 & 21.4 \\
\hline \multicolumn{8}{|c|}{ Reducing symptomatic infections and stopping virus transmission } \\
\hline Subtotal & 1656.6 & 182.5 & 223.9 & 139.0 & 181.8 & 462.9 & 466.5 \\
\hline Adults without conditions & 1656.6 & 182.5 & 223.9 & 139.0 & 181.8 & 462.9 & 466.5 \\
\hline Totalt & 3098.6 & 321.5 & 431.6 & 253.0 & 427.0 & 873.9 & 791.5 \\
\hline \multicolumn{8}{|l|}{$80 \%$} \\
\hline \multicolumn{8}{|l|}{ Maintaining essential core societal services } \\
\hline Subtotal & 206.6 & 20.3 & 35.6 & 25.5 & 50.4 & 47.0 & 27.8 \\
\hline Healthcare workers & 32.6 & 1.1 & 8.7 & 1.4 & 8.6 & 8.5 & 4.2 \\
\hline Police and military* & 37.5 & 2.6 & 6.4 & 4.9 & 6.7 & 8.6 & 8.3 \\
\hline Other occupational population & 136.6 & 16.6 & 20.5 & 19.2 & 35.0 & 30.0 & 15.3 \\
\hline \multicolumn{8}{|l|}{ Reducing severe covid-19 } \\
\hline Subtotal & 1716.0 & 165.0 & 241.5 & 126.6 & 276.6 & 501.0 & 405.4 \\
\hline $\begin{array}{l}\text { People aged } \geq 60 \text { years with at least one } \\
\text { underlying condition }\end{array}$ & 526.1 & 28.6 & 90.5 & 28.6 & 115.8 & 158.3 & 104.2 \\
\hline $\begin{array}{l}\text { People aged } \geq 80 \text { years without any underlying } \\
\text { conditions }\end{array}$ & 22.9 & 0.6 & 3.6 & 0.6 & 5.8 & 8.6 & 3.5 \\
\hline $\begin{array}{l}\text { People aged } 60-79 \text { years without any } \\
\text { underlying conditions }\end{array}$ & 283.3 & 15.2 & 41.0 & 12.6 & 49.2 & 105.6 & 59.7 \\
\hline $\begin{array}{l}\text { People aged } 20-59 \text { years with at least one } \\
\text { underlying condition }\end{array}$ & 770.2 & 89.3 & 94.6 & 69.6 & 96.9 & 210.2 & 209.6 \\
\hline Pregnant women & 113.6 & 31.3 & 11.9 & 15.0 & 8.8 & 18.2 & 28.5 \\
\hline \multicolumn{8}{|c|}{ Reducing symptomatic infections and stopping virus transmission } \\
\hline Subtotal & 2208.8 & 243.4 & 298.5 & 185.3 & 242.4 & 617.2 & 622.0 \\
\hline Adults without conditions & 2208.8 & 243.4 & 298.5 & 185.3 & 242.4 & 617.2 & 622.0 \\
\hline Totalt & 4131.4 & 428.7 & 575.5 & 337.3 & 569.4 & 1165.2 & 1055.4 \\
\hline
\end{tabular}

Pacific (58.8 million people, 22.8\%), and the Americas (44.5 million people, 17.2\%; table 1 and fig 3, fig 4, fig 5). The size of the population at high risk of severe covid-19 and those to vaccinate to contain covid-19 are highest in the Western Pacific (1.4 billion) and South East Asia (1.3 billion).

The size of age specific target population groups also varies markedly across regions. Few people are older than 80 years in Africa while a considerable proportion live in Europe and North America (fig S2). The working age population accounts for a substantially larger proportion of the total population than other target populations in all regions. Additionally, the proportion of people younger than 20 years is relatively high in Africa compared with other regions (fig S2).

If people with a history of SARS-CoV-2 infection are excluded from vaccine priority groups, regional differences become more accentuated. The largest decrease in the number of doses needed is found in Europe relative to the base scenario (table S4).

\section{National perspectives}

Here we focus on 104 countries with high quality data collected from official reports, covering $74.4 \%$ (5.8 billion) of the world population. Sizable heterogeneity emerges in the distribution of different target population groups, ranging from 1000 to 1.4 billion people (figs S3, S4 and table S7). National estimates of the size of target populations suggest that six countries-China, India, the US, Pakistan, Brazil, and Nigeria-have the largest share of the total target population (fig 6 and figs S3, S4). In contrast, countries in Africa and the Eastern Mediterranean account for a relatively low share (figs S5, S6 and figs S7, S8). 


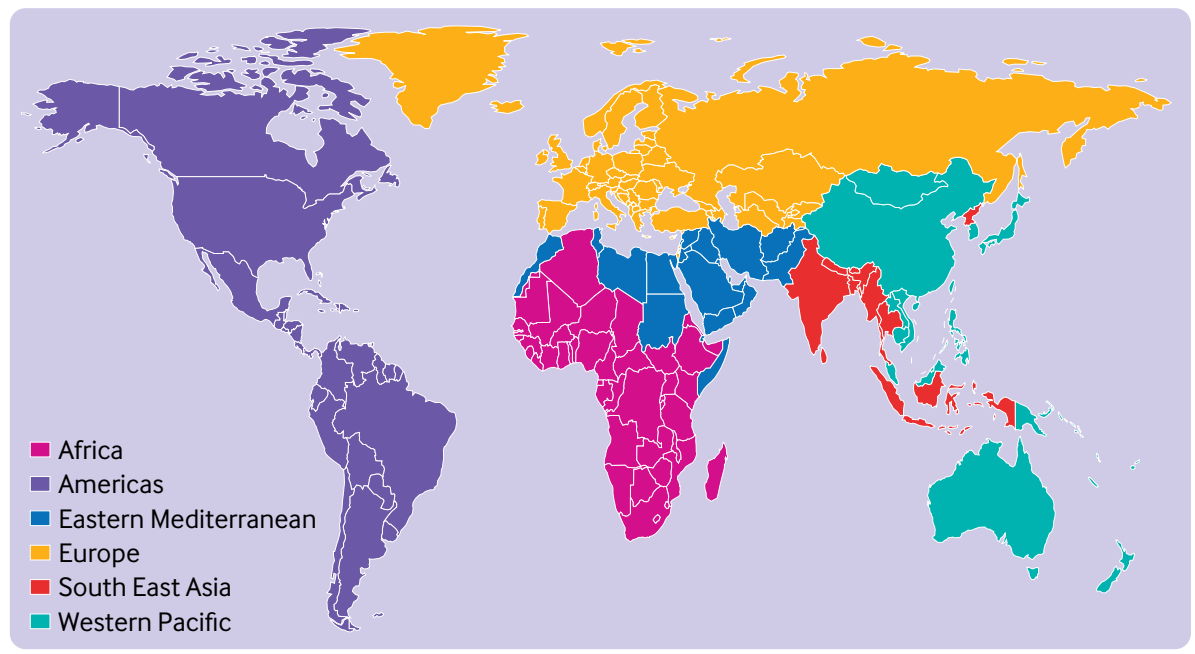

Fig 3 | Geographical distribution of member states by World Health Organization region

When we consider country specific willingness to be vaccinated, geographical disparities in the distribution of target population sizes do not substantially change (table S8). We also found that the target population that maintains essential core societal function, based on our definition, is more predominant in middle and high income countries (fig 6 and fig S7). Moreover, we observed between country variations in the size of the target population to reduce severe disease or to contain SARS-CoV-2 transmission, with $14.1 \%$ (1.1 billion) and $30.1 \%$ (2.3 billion), respectively, of the total world

\section{Goal 1}

- Healthcare workers

- Police and military

Other essential workers

Goal 2

- People aged $\geq 60$ years with at least one underlying condition

- People aged $\geq 80$ years without any underlying conditions

- People aged $60-79$ years without any underlying conditions

- People aged $<60$ years with at least one underlying condition

- Pregnant women

Goal 3

Healthy adults (20-59 years)

School aged children and young people (5-19 years)

Young children (0-4 years)

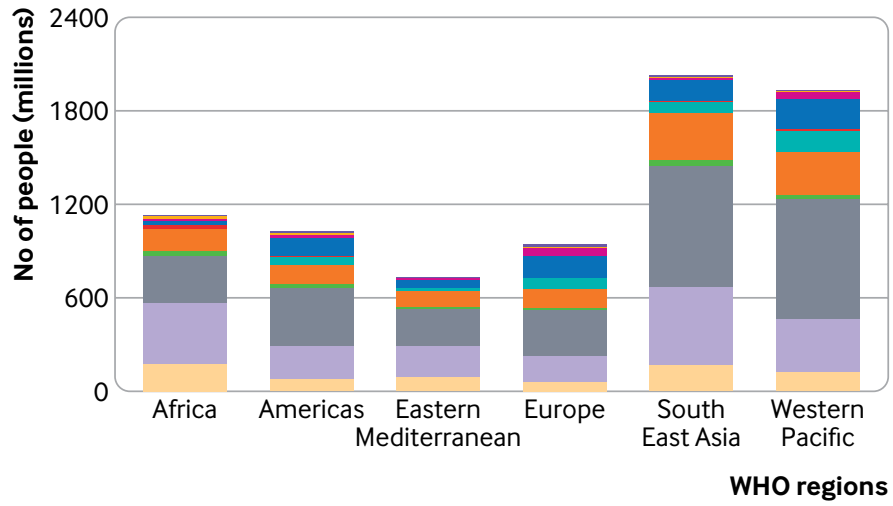

Fig 4 | Regional estimates of target population sizes for covid-19 vaccination by goal of vaccination programmes. Covid-19=coronavirus disease 2019 population found in China, India, the US, Japan, and Brazil (fig 6, fig S8).

For the 11 countries lacking data on age specific prevalence of underlying conditions, our estimates of the target populations were robust to changes in modelling assumptions (table S4 $v$ table S6).

\section{Discussion}

We identified target population groups according to three different goals of covid-19 vaccination programmes aimed at maintaining essential societal functions, minimising severe disease, and interrupting transmission. We quantified the size of each target group on a global, regional, and country level. Important variations were observed in the amount of vaccines needed depending on the goals of the vaccination programme, and the distribution of target populations was found to vary within and between regions. In particular, we estimate the demand for vaccines would be high for essential workers and high risk populations with health conditions, with the second group accounting for $27.7 \%$ (2.2 billion) of the total world population.

\section{Implications of findings}

By assuming a two dose vaccine schedule, we estimate that approximately 15.6 billion doses of covid-19 vaccines will be required by the 194 WHO member states for a universal covid-19 vaccination programme (table S4), and 10.3 billion for targeted occupational or high risk groups. Twelve covid-19 vaccine manufacturers have announced that about 10 billion doses will be available by the end of 2021 (table S9). In the most optimistic scenario that this figure is actually reached, it would take about six to seven months to produce enough vaccines to achieve herd immunity by protecting at least $60-80 \%$ of the world population (4.7-6.2 billion). Even if manufacture of candidate vaccines is going smoothly, this is just the first step in a long process to deliver vaccines to populations, and other monumental challenges will be faced (eg, 


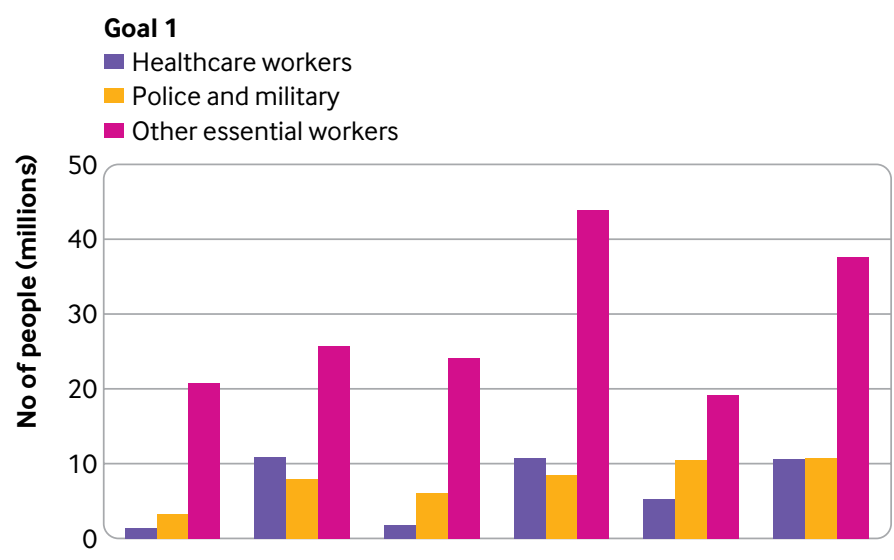

\section{Goal 2}

- People aged $\geq 60$ years with at least one underlying condition

- People aged $\geq 80$ years without any underlying conditions

- People aged 60-79 years without any underlying conditions

- People aged $<60$ years with at least one underlying condition

Pregnant women

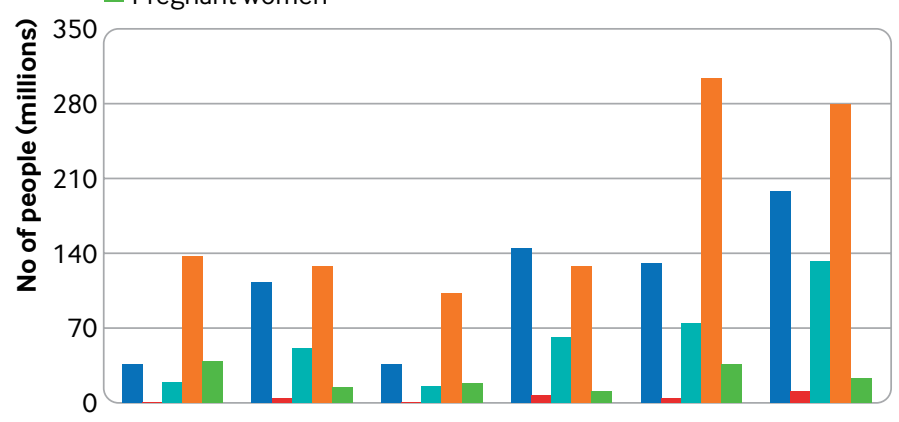

\section{Goal 3}

Healthy adults (20-59 years)

School aged children and young people (5-19 years)

Young children (0-4 years)

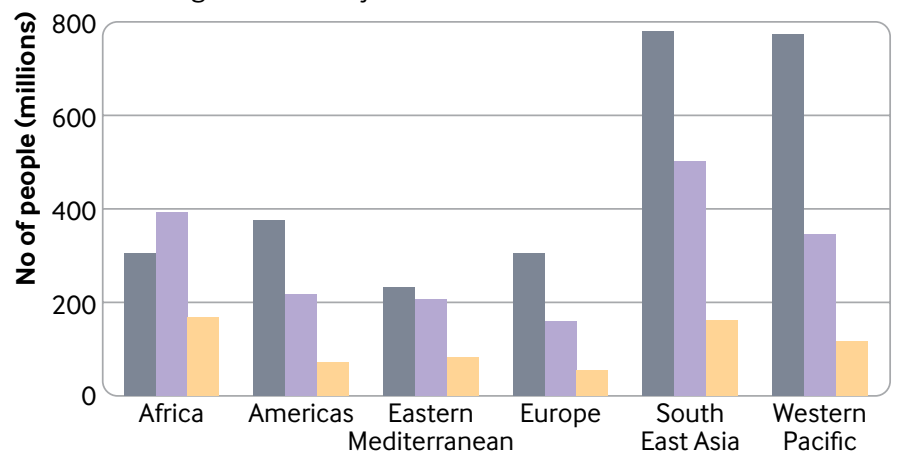

WHO regions

Fig 5 | Upper panel: regional estimates of number of essential workers who are critical to maintaining a functional society. Middle panel: regional estimates of number of vulnerable people to be vaccinated to reduce severe covid-19. Lower panel: regional estimates of number of people that need to be vaccinated to contain transmission. Covid-19=coronavirus disease 2019 supply chains. ${ }^{28}$ Therefore, substantial investment is needed to strengthen international and national supply chains, especially to guarantee the distribution of vaccines in rural and remote communities in many developing countries.

A sufficient level of vaccine acceptance in any given country or region will be needed to reach herd immunity and prevent community spread of SARSCoV-2. As exemplified by other vaccine preventable diseases (eg, the 2019 measles outbreak in the US ${ }^{29}$ ), vaccine hesitancy could hamper the beneficial effects of vaccination campaigns. ${ }^{30}$ Based on our metaanalysis of recent surveys, an estimated $68.4 \%$ (95\% confidence interval $64.2 \%$ to $72.6 \%$ ) of the world population is willing to receive covid-19 vaccination, although this estimate will probably change over time as incidence increases or decreases. Although our meta-analysis highlighted regional differences in acceptance of covid-19 vaccines, these differences did not substantially influence our estimates on a regional level. However, such differences could play a larger role on a national (or subnational) scale.

In a scenario of limited vaccine availability at the beginning of a covid-19 vaccination programme, the same barriers would apply to all target groups, but vaccination of targeted occupational or high risk groups will probably be more feasible than the general public without any underlying conditions. These groups together comprise an estimated 2.5 billion people in the 194 WHO member states. Disparities in availability and distribution of covid-19 vaccine within and between regions should also be borne in mind. These disparities will result in different durations of vaccination programmes owing to global limitations in vaccine production, supply capacity, and market forces. For example, in countries with sufficient local capacity for vaccine production and supply to meet the national demand (eg, the US and China), vaccination of a substantial proportion of priority groups could be achieved in a few months. However, the process could last much longer in low and middle income countries, which have lower capacity to secure and deliver vaccines. ${ }^{31}$ Ongoing challenges remain in bringing a covid-19 vaccine to the market alongside endorsements of needs based allocation principles. ${ }^{161820}$ One of the biggest challenges is the lack of a procedural governance mechanism to enforce these allocation principles on a global level. To a large extent, access to the vaccine will be determined by market mechanisms and altruism rather than central planning. Therefore, as efforts to bring covid-19 vaccines to the market progress, international institutions, national governments, and manufacturers need to work out vaccine allocation plans and negotiate affordable prices. ${ }^{32}$

In addition to the direct benefits of vaccination (protection of vaccinated people from infection, reduction in illnesses, and mortality rates), prioritisation should also balance the indirect benefits of a vaccine programme that reduces virus circulation in a community because vaccinated people are less likely to be infected and transmit the virus. ${ }^{31}$ In particular,
International and national supply chains will probably limit the worldwide and nationwide distribution of covid-19 vaccines. WHO reports that vaccine wastage amounts to approximately $50 \%$ every year, often because of inadequate temperature control of the 
indirect benefits might be important to protect people older than 65 years who are at increased risk of severe disease and also possibly less likely to be directly protected by vaccination because of immune senescence. ${ }^{32}$ Therefore, the effectiveness of different vaccine candidates against infection, severe disease, and transmission should be considered when designing a vaccination programme if several vaccines

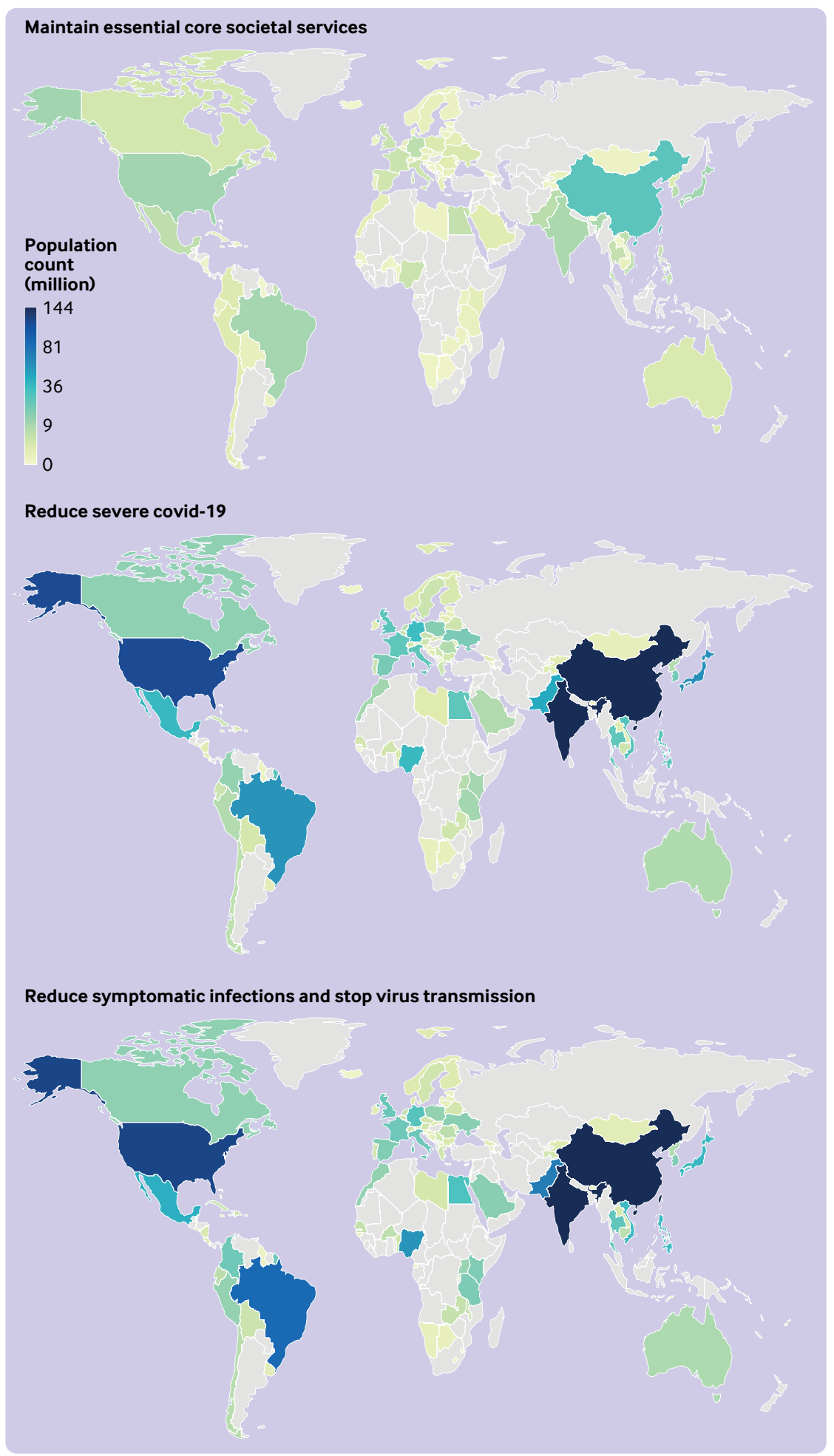

Fig 6 | Estimates of target population sizes for covid-19 vaccination programmes in 104 countries with robust data on occupation and high risk groups by goal of vaccination programme. Upper panel: target populations to maintain essential core societal services; middle panel: target populations to reduce severe covid-19; lower panel: target populations to reduce symptomatic infections and stop virus transmission. Empty cells represent lack of data on target populations. Covid-19=coronavirus disease 2019 
become available concomitantly. For instance, a highly effective vaccine against severe disease could be administered to shield essential workers and the most vulnerable groups, maintain a functional society, and lower covid-19 burden. At the same time, a less effective vaccine against infection could still be distributed to the general adult population and might contribute to reaching the herd immunity threshold.

We were unable to collect data on population stratified by occupation in $25.8 \% \quad(n=50)$ of the countries considered. Excluding these data from the analysis would lead to the exclusion of a substantial proportion of the total population (around 0.86 billion people, $11 \%$ ), and would make it difficult to understand global heterogeneity in the distribution of each target population. Therefore, we included these countries in regional and global estimates, and used an imputation algorithm. ${ }^{26}$ Unlike other approaches that use values imputed from average numbers, however, this algorithm considers uncertainty in the missing values by creating several different plausible imputed datasets from their predictive distribution (based on the observed data). Variability between the imputed datasets can be considered, and average estimates can be obtained. ${ }^{33}$ This approach gives more robust estimates of the size of the target populations on local, regional, and global scales.

\section{Limitations of study}

A few limitations of the study should be highlighted. Firstly, lack of timely data for 2020 constrains estimates of population sizes in many countries. However, the distribution of target occupational and high risk groups is probably stable over a few years. Secondly, we could not explore variations in target populations within countries. Policy makers should investigate and discuss actual vaccine allocation plans when more local data become available in their country. Thirdly, owing to unavailability of data, we could not provide estimates of the size of the target population among other essential workers (eg, people working in the finance and economy sector) or estimate target population sizes by other demographic factors, such as racial and ethnic groups, which are reported to be risk factors for covid-19 and adverse outcomes. ${ }^{34} 35$ Additionally, given the relatively low prevalence of underlying conditions among essential workers younger than 60 years $(5.8 \%, 95 \%$ confidence interval $5.7 \%$ to $6.1 \%),{ }^{36}$ we did not subtract these essential workers with underlying conditions from the broader group of adults with underlying conditions.

Another key question when planning covid-19 vaccination programmes is whether people with a confirmed history of SARS-CoV-2 infection should be included in priority groups. Currently, the duration and level of protection after natural SARS-CoV-2 infection remain unclear. Inclusion or exclusion criteria for eligible participants in clinical trials of candidate covid-19 vaccines are still heterogeneous, with some including people with a history of infections (table S10). In practice, excluding people with a history of SARS-CoV-2 infection might generate logistic and ethical challenges because serological screening would be required and the accuracy of the test should be taken into consideration. As the number of people with covid-19 continues to mount globally, the outbreak trajectory in the coming months will depend on individual countries' intervention policies and reactive population behaviour, both of which are unpredictable. Deprioritising people with a confirmed history of SARS-CoV-2 infection could substantially reduce the number of doses required for vaccination programmes, at least in the early stages. Discounting previous infections will become more sizable over time as the numbers of people with covid-19 accumulate.

Finally, it is important to emphasise that the priority groups considered in this study represent a starting point and will probably evolve. Priority groups could be updated as the pandemic progresses and more evidence is collected about the epidemiology of covid-19 and its effect on society. For instance, new pre-existing conditions might be added to the existing risk factors for severe SARS-CoV-2 infection, therefore expanding the number of people considered to be most vulnerable. The same could apply to essential workers as new essential services might be identified to keep society running as the pandemic enters its second year. Such dynamic changes in priority groups might be even more important if the goal of the vaccination programme is to limit SARS-CoV-2 transmission. For example, at the onset of the pandemic, older students did not appear to be major players in spreading the infection, while more evidence is accumulating to show that they could partially contribute to amplifying community transmission. ${ }^{37}$

\section{Conclusions and policy implications}

Findings from this study provide an evidence base for global, regional, and national vaccine prioritisation and allocation. Variations in the size of the target populations within and between regions emphasise the tenuous balance between vaccine demand and supply, especially in low and middle income countries without sufficient capacity to meet domestic demand for covid-19 vaccine. This study presents a strategy for vaccine allocation based on three main goals, which should be considered as a general framework when discussing and evaluating plans. Other additional factors such as availability of vaccines for initial distribution, epidemiological situation, and vaccine hesitancy should be taken into account by individual countries to refine allocation plans.

Contributors: WW, QW, and HY had full access to all of the data in the study and take responsibility for the integrity of the data and the accuracy of the data analysis. CV, MA, and HY were responsible for its conception and design. WW, QW, KD, XingC, XB, XinhC, and ZC were responsible for the acquisition, analysis, or interpretation of data. WW, QW, JY, CV, MA, and HY drafted the manuscript. JY, CV, MA, and $H Y$ made critical revision of the manuscript for important intellectual content. WW, QW, XingC, and XB did the data analysis. JY, CV, and MA provided administrative, technical, or material support. CV, MA, and 
$\mathrm{HY}$ are joint senior authors and contributed equally to this work. HY is the guarantor. The corresponding author attests that all listed authors meet authorship criteria and that no others meeting the criteria have been omitted.

Funding: The study was funded by the National Science Fund for Distinguished Young Scholars (No 81525023), Key Emergency Project of Shanghai Science and Technology Committee (No 20411950100), and National Science and Technology Major Project of China (No 2018ZX10713001-007, No 2017ZX10103009-005, No 2018ZX10201001-010). The funders had no role in the design and conduct of the study; collection, management, analysis, and interpretation of the data; preparation, review, or approval of the manuscript; and decision to submit the manuscript for publication. Competing interests: All authors have completed the ICMJE uniform disclosure form at www.icmje.org/coi_disclosure.pdf and declare: support from the National Science Fund for Distinguished Young Scholars, Key Emergency Project of Shanghai Science and Technology Committee, and National Science and Technology Major Project of China for the submitted work; MA has received research funding from Seqirus and $\mathrm{HY}$ has received research funding from Sanofi Pasteur, GlaxoSmithKline, Yichang HEC Changjiang Pharmaceutical Company, and Shanghai Roche Pharmaceutical Company. None of those research funding is related to covid-19. All other authors report no competing interests.

Ethical approval: Not required.

Data sharing: The datasets used and analysed during the current study are available in appendix.

The lead author affirms that the manuscript is an honest, accurate, and transparent account of the study being reported; that no important aspects of the study have been omitted; and that any discrepancies from the study as planned have been explained.

\section{Dissemination to participants and related patient and public} communities: Because this research uses global population data, there are no plans for disseminating this research to specific participants or patients beyond publishing it.

Provenance and peer review: Not commissioned; externally peer reviewed.

Publisher's note: Published maps are provided without any warranty of any kind, either express or implied. BMJ remains neutral with regard to jurisdictional claims in published maps.

This is an Open Access article distributed in accordance with the Creative Commons Attribution Non Commercial (CC BY-NC 4.0) license, which permits others to distribute, remix, adapt, build upon this work non-commercially, and license their derivative works on different terms, provided the original work is properly cited and the use is noncommercial. See: http://creativecommons.org/licenses/by-nc/4.0/.

1 World Health Organization. DRAFT landscape of COVID-19 candidate vaccines-12 November 2020

2 World Health Organization. Coronavirus disease 2019 (COVID-19) situation report - 2092020 https://www who int/docs/defaultsource/coronaviruse/situation-reports/20200914-weekly-epiupdate-5.pdf?sfvrsn=cf929d04_2.

3 Sutton M. Cieslak P, Linder M. Notes from the field: seroprevalence estimates of SARS-CoV-2 infection in convenience sample - Oregon, May 11-June 15, 2020. MMWR Morb Mortal Wkly Rep 2020:69:1100-1. doi:10.15585/mmwr.mm6932a4

4 Pollán M, Pérez-Gómez B, Pastor-Barriuso RENE-COVID Study Group. Prevalence of SARS-CoV-2 in Spain (ENE-COVID): a nationwide, population-based seroepidemiological study. Lancet 2020;396:53544. doi:10.1016/S0140-6736(20)31483-5

5 Stringhini S, Wisniak A, Piumatti G. Seroprevalence of anti-SARS CoV-2 IgG antibodies in Geneva, Switzerland (SEROCoV-POP): a population-based study. Lancet 2020;396:313-9. doi:10.1016/ S0140-6736(20)31304-0

6 Chen X, Chen Z, Azman AS. Serological evidence of human infection with SARS-CoV-2: a systematic review and meta-analysis.medRxiv . 2020:2020.09.11.20192773. doi:10.1101/2020.09.11.20192773

7 AstraZeneca. AstraZeneca concludes agreement with the European Commission for the supply of up to 400 million doses of AZD1222 COVID-19 vaccine. 2020. https://www.astrazeneca.com/mediacentre/press-releases/2020/astrazeneca-concludes-agreementwith-the-european-commission-for-the-supply-of-up-to-400-milliondoses-of-azd1222-covid-19-vaccine.html.

8 Bharat Biotech. Bharat Biotech inks licensing deal with Washington University School of Medicine in St. Louis to advance COVID-19 intranasal vaccine technology. 2020. https://www.bharatbiotech.
com/images/press/Bharat-Biotech-Inks-licensing-deal-withwashington-university-school-to-advance-COVID-19-intranasalvaccine.pdf.

9 Johnson \& Johnson. Johnson \& Johnson initiates pivotal global phase 3 clinical trial of lanssen's covid-19 vaccine candidate. 2020. https:// www.jni.com/johnson-johnson-initiates-pivotal-global-phase-3clinical-trial-of-janssens-covid-19-vaccine-candidate.

10 Moderna. Moderna announces supply agreement with the Ministry of Public Health to supply Qatar with mRNA vaccine against covid-19 (mRNA-1273). 2020. https://investors.modernatx.com/ news-releases/news-release-details/moderna-announces-supplyagreement-ministry-public-health-supply.

11 Novavax. Novavax and Commonwealth of Australia announce agreement in principle for acquisition of Novavax covid-19 vaccine. 2020. https://ir.novavax.com/node/15226/pdf.

12 Revista Pesquisa Fapesp. Centros nacionais de pesquisa negociam a importação de tecnologia para produção de vacinas. 2020. https:// revistapesquisa.fapesp.br/para-ganhar-tempo/.

13 Pfizer. Pfizer and BioNTech announce vaccine candidate against covid-19 achieved success in first interim analysis from phase 3 study. 2020. https://www.pfizer.com/news/press-release/pressrelease-detail/pfizer-and-biontech-announce-vaccine-candidateagainst.

14 Pagliusi S, Jarrett S, Hayman B. Emerging manufacturers engagements in the COVID -19 vaccine research, development and supply. Vaccine 2020:38:5418-23. doi:10.1016/j. vaccine.2020.06.022

15 World Health Organization. Coronavirus disease (covid-19)-herd immunity. 2020. https://www.who.int/emergencies/diseases/novelcoronavirus-2019/media-resources/science-in-5/episode-1.

16 Emanuel EJ, Persad G, Kern A. An ethical framework for global vaccine allocation. Science 2020;369:1309-12. doi:10.1126/science. abe2803

17 World Health Organization. The access to covid-19 tools. Accelerator 2020.

18 Toner E, Barnill A, Krubiner C, et al. Interim framework for covid-19 vaccine allocation and distribution in the United States. Johns Hopkins Bloomberg School of Public Health. 2020.

19 Joint Committee on Vaccination and Immunisation. Interim advice on priority groups for COVID-19 vaccination. Department of Health \& Social Care, United Kingdom. 18 June 2020

20 World Health Organization. A global framework to ensure equitable and fair allocation of covid-19 products and potential implications for covid-19 vaccines. 18 June 2020

21 The Lancet. The plight of essential workers during the COVID-19 pandemic. Lancet 2020:395:1587. doi:10.1016/S01406736(20)31200-9

22 Clark A, Jit M, Warren-Gash CCentre for the Mathematical Modelling of Infectious Diseases COVID-19 working group. Global, regional, and national estimates of the population at increased risk of severe COVID-19 due to underlying health conditions in 2020: a modelling study. Lancet Glob Health 2020;8:e1003-17. doi:10.1016/S2214109x(20)30264-3

23 Zhang J, Litvinova M, Liang Y. Changes in contact patterns shape the dynamics of the COVID-19 outbreak in China. Science 2020;368:1481-6. doi:10.1126/science.abb8001

24 Litvinova M, Liu Q-H, Kulikov ES, Ajelli M. Reactive school closure weakens the network of social interactions and reduces the spread of influenza. Proc Natl Acad Sci U S A 2019;116:13174-81. doi:10.1073/pnas.1821298116

25 Mossong J, Hens N, Jit M. Social contacts and mixing patterns relevant to the spread of infectious diseases. PLoS Med 2008;5:e74 doi:10.1371/journal.pmed 0050074

26 van Buuren S, Groothuis-Oudshoorn K. mice: multivariate imputation by chained equations in R. J Stat Soft 2011;45(3) doi:10.18637/jss. v045.i03.

27 Malik AA, McFadden SM, Elharake J, Omer SB. Determinants of COVID-19 vaccine acceptance in the US. EClinicalMedicine 2020;26:100495. doi:10.1016/i. eclinm.2020.100495

28 World Health Organization. Monitoring vaccine wastage at country level: guidelines for programme managers. WHO, 2005.

29 Benecke O, DeYoung SE. Anti-vaccine decisionmaking and measles resurgence in the United States. Glob Pediatr Health 2019;6:2333794X19862949. doi:10.1177/2333794X19862949

30 Johnson NF, Velásquez N, Restrepo NJ. The online competition between pro- and anti-vaccination views. Nature 2020;582:230-3. doi:10.1038/s41586-020-2281-1

31 Anderson RM, May RM. Vaccination and herd immunity to infectious diseases. Nature 1985;318:323-9. doi:10.1038/ $318323 \mathrm{a} 0$

32 Castle SC. Clinical relevance of age-related immune dysfunction. Clin Infect Dis 2000;31:578-85. doi:10.1086/313947 
33 Sterne JAC, White IR, Carlin JB. Multiple imputation for missing data in epidemiological and clinical research: potential and pitfalls. BMJ 2009;338:b2393. doi:10.1136/bmj.b2393

34 Khunti K, Singh AK, Pareek M, Hanif W. Is ethnicity linked to incidence or outcomes of covid-19?BMJ 2020;369:m1548. doi:10.1136/bmj.m1548

35 Williamson EJ, Walker AJ, Bhaskaran K. Factors associated with COVID-19-related death using OpenSAFELY. Nature 2020;584:4306. doi:10.1038/s41586-020-2521-4

36 Silver SR, Li J, Boal WL, Shockey TL, Groenewold MR. Prevalence of underlying medical conditions among selected essential critical infrastructure workers - behavioral risk factor surveillance system, 31 States, 2017-2018. MMWR Morb Mortal Wkly Rep 2020;69:1244-9. doi:10.15585/mmwr.mm6936a3

37 Grech V, Grech E, Borg Myatt J. Holidays over: a review of actual COVID-19 school outbreaks up to September 2020. Early Hum Dev 2020;105206. doi:10.1016/j.earlhumdev.2020.105206

Web appendix: Appendix 